Check for updates

The BMJ

Cite this as: BMJ2020;370:m3257 http://dx.doi.org/10.1136/bmj.m3257 Published: 18 August 2020

\section{Public Health England is axed in favour of new health protection agency}

\section{Gareth lacobucci}

The government plans to abolish Public Health England (PHE) and replace it with a new agency that will specifically deal with preparation for pandemics.

The shake-up will see PHE merge with the NHS Test and Trace service and the Joint Biosecurity Centre to form a new agency, the National Institute for Health Protection, under a single leadership team.

The new agency will start work immediately to lead England's ongoing response to the pandemic. It will formally operate from spring 2021, with a primary focus on public health protection and infectious disease capability.

Announcing the changes in a speech hosted by the Policy Exchange think tank, England's health secretary, Matt Hancock, said, "One of the lessons from the crisis is that we need an institution whose only job is to prepare for and respond to external threats like pandemics.

"We can learn from countries like South Korea and Germany's Robert Koch Institute, where their health protection agencies have a huge primary focus on pandemic response. We will build the same focus here."

\section{Wider failings}

PHE, which employs around 5500 full time staff across its wide remit of health protection and health prevention, has faced criticism over aspects of its response to the covid-19 pandemic, including its handling of testing and tracing of contacts. But healthcare leaders said that the agency, which formed in 2013, was being scapegoated by ministers who were ultimately responsible for the country's response to covid-19.

Chaand Nagpaul, the BMA's chair of council, said, "We must absolutely not allow PHE and its staff to shoulder the blame for wider failings and government decisions."

The government said that it would consult on the future of PHE's health prevention functions over the next six months to decide where they should move to in the system.

Dido Harding, the head of NHS Test and Trace and chair of the regulator NHS Improvement, will serve as interim executive chair of the new agency, and Michael Brodie, current chief executive of the NHS Business Services Authority, will serve as interim chief executive during the transition period. The outgoing PHE chief executive, Duncan Selbie, will become an adviser to the Department of Health and Social Care.

Hancock emphasised that the new organisation would have a local focus and would work closely with local directors of public health and their teams, whom he described as "mission critical" to the country's covid response.

But healthcare experts said that it was not clear what problem the government was trying to solve.

Nigel Edwards, chief executive of the Nuffield Trust, said, "The government risks making a major misstep by dismantling its own public health agency at such a crucial time, creating a huge distraction for staff who should be dedicating themselves to the next stage of the pandemic. There is no clear argument as to why this rebranding and reshuffling will solve some of the problems highlighted by the secretary of state."

Richard Murray, chief executive of the King's Fund, said, "Undoubtedly, there are questions to be answered about England's handling of the covid-19 crisis, but the middle of a pandemic is not the time to dismantle England's public health agency." 